\title{
Tunable multi-stage wettability and adhesion force on polymer brushes triggered by temperature and $\mathrm{pH}$
}

\author{
Shuang Zhang ${ }^{1 \dagger}$, Jian Wang ${ }^{1 \dagger}$, Xuewei Zhang ${ }^{1}$, Wenlong Song ${ }^{1 *}$ and Shutao Wang ${ }^{2,3}$
}

Smart wettable surface is the base of constructing microfluidic devices and protein chips for highly functional integration under different extra-stimuli [15]. The responsive wettability could endow the microchannels with the ability of controlling liquid behaviors [6-8], and meanwhile the stable wettable region on the surface would ensure a stable liquid flow in the microchannels. In recent years, responsive wettable surfaces under different stimuli including temperature [9-11], pH [12-14], light [15-17], electric [18-20] and magnetic field [21-23] are realized by atom transfer radical polymerization (ATRP) [24], electrochemical deposition [25], chemical/physical vapor deposition $[26,27]$, self-assembly [28], template method [29] and so on. For these single-stimuli responsive wettable surfaces, there are two stable wettable regions before and after being triggered by the stimuli. In recent years, multistimuli wettable materials have attracted more attention due to their applications in controlled drug release [30], protein adsorption [31], and catalysis [32]. These multistimuli wettable surfaces are aiming to integrate more functions on the smart devices, such as dual-responsive (temperature and $\mathrm{pH}[33,34]$, temperature and light [35], $\mathrm{pH}$ and light [31], voltage and $\mathrm{pH}$ [36]) and threeresponsive (temperature, glucose and $\mathrm{pH}$ ) wettable surfaces [30]. Single-stage wettability change, namely two stable wettable regions (hydrophilic and hydrophobic), can be observed before and after stimulated in these studies.

Hack et al. [37] reported a three-stage wettable surface based on poly[2-(methacryloyloxy)ethyl] phosphate (PMAEP) brushes containing phosphate groups triggered by $\mathrm{pH}$. This unique wetting property could be attributed to the different chemical states derived from the association-dissociation equilibrium of phosphate groups in different $\mathrm{pH}$ [38]. Besides, we reported a temperatureresponsive three-stage wettable surface synthesized by poly $(N$-isopropylmethacrylamide $)-b$-poly $(N$-isopropylacrylamide) (PNIPMAM- $b$-PNIPAM) brushes [39]. The surfaces exhibited three stable wettable regions corresponding to the two lower critical solution temperature (LCST) of PNIPAM $\left(32^{\circ} \mathrm{C}\right)$ and PNIPMAM $\left(44^{\circ} \mathrm{C}\right)$, at which phase inversion occurred and resulted in the transition from hydrophility to hydrophobicity. However, these reports mainly focus on the multi-stage wettable surfaces triggered by single stimulus. It is still challenging to fabricate the multi-stage wettable surface triggered by multi-stimuli for integrating more complex functions to the smart wettable device in the application of cell capture and release [40]. Herein, the polymer brushes composed of PNIPMAM- $b$-(PNIPAM-co-PMAEP) were synthesized on silicon substrate by ATRP, and their multi-stage wettable property triggered by temperature and $\mathrm{pH}$ was investigated. The surface adhesion force of the polymer brushes was observed under different temperature and $\mathrm{pH}$ by atom force microscopy (AFM).

As shown in Fig. 1a, PNIPMAM brushes were firstly grafted onto the silicon substrate by ATRP, and then the active bromine atoms at the end of PNIPMAM chains were capped, which could be used to re-initiate polymerization of another acrylamide monomers by adding the fresh catalysis based on the principle of ATRP $[41,42]$. Subsequently, NIPAM and MAEP monomers were polymerized upon the end of PNIPMAM chains. The polymerization process was investigated by Fourier transform infrared spectroscopy (FTIR) (Fig. 1b). For the

\footnotetext{
${ }^{1}$ The State Key Laboratory of Supramolecular Structure and Materials, College of Chemistry, Jilin University, Changchun 130023, China

${ }^{2}$ CAS Key Laboratory of Bio-inspired Materials and Interfacial Science, CAS Center for Excellence in Nanoscience, Technical Institute of Physics and Chemistry, Chinese Academy of Sciences, Beijing 100190, China

${ }^{3}$ University of Chinese Academy of Sciences, Beijing 100049, China

† These authors contributed equally to this work.

* Corresponding author (email: songwenlong@jlu.edu.cn)
} 

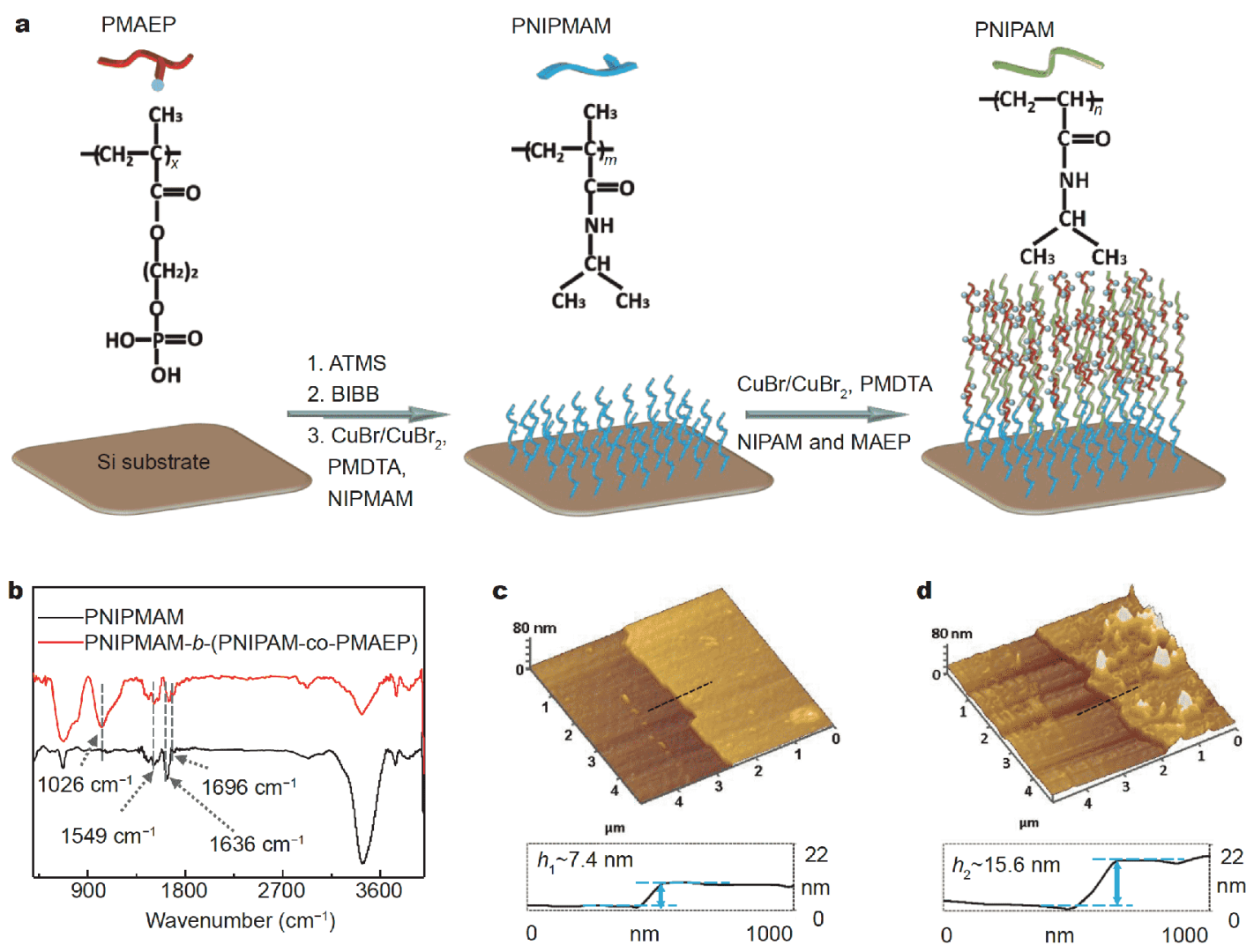

Figure 1 (a) The preparation of the dual-responsive PNIPMAM- $b$-(PNIPAM-co-PMAEP) brushes by ATRP. (b) The FTIR spectra of PNIPMAM brushes (black line) and PNIPMAM- $b$-(PNIPAM-co-PMAEP) brushes (red line). (c, d) The thickness of PNIPMAM brushes and PNIPMAM- $b$ (PNIPAM-co-PMAEP) brushes measured by AFM.

PNIPMAM brushes (black line), the absorption peak at $1,696 \mathrm{~cm}^{-1}$ is corresponding to the $\mathrm{C}=\mathrm{O}$ stretching vibration in amide group, and the peaks of $1,636 \mathrm{~cm}^{-1}$ and $1,549 \mathrm{~cm}^{-1}$ are ascribed to $-\mathrm{NH}_{2}$ bending vibration in amide group, which indicates that PNIPMAM is synthesized on the substrate successfully. The similar absorption peaks can be also observed on the FTIR spectra of PNIPMAM- $b$-(PNIPAM-co-PMAEP) brushes (red line in Fig. 1b), NIPAM and NIPMAM monomer (Fig. S1). Moreover, compared with the PNIPMAM brushes, an absorption peak at $1,026 \mathrm{~cm}^{-1}$ of PNIPMAM$b$-(PNIPAM-co-PMAEP) brushes and MAEP monomer (Fig. S1) is assigned to the $\mathrm{P}-\mathrm{O}$ stretching vibrations, which indicates that PMAEP is grafted on the substrate. The thickness of PNIPMAM and PNIPMAM- $b$-(PNIPAM-co-PMAEP) brush films is about 7.4 and $15.6 \mathrm{~nm}$, respectively (Fig. 1c and d). These results illustrate that NIPMAM, NIPAM and MAEP monomers have been grafted on the substrate successfully.

The temperature-responsive wettable behavior of PNIPMAM- $b$-(PNIPAM-co-PMAEP) brushes was inves- tigated on a DataPhysics OCA20 system with a temperature controller (Fig. 2). The contact angle (CA) increased with the temperature; and two wettable inflexions were found at about 32 and $44^{\circ} \mathrm{C}$, which are consistent with the two LCSTs of PNIPAM and PNIPMAM, respectively. Consequently there were three relatively stable wettable stages corresponding to three temperature ranges $\left(T<32^{\circ} \mathrm{C}, 32^{\circ} \mathrm{C}<T<44^{\circ} \mathrm{C}, T>44^{\circ} \mathrm{C}\right)$. When the temperature was below the LCST $\sim 32^{\circ} \mathrm{C}$ of PNIPAM, the polymer brushes exhibited relatively stable wetting region with $\mathrm{CA}$ about $62^{\circ}$. When the temperature rised to the range between $32^{\circ} \mathrm{C}$ and the LCST $\sim 44^{\circ} \mathrm{C}$ of PNIPMAM, the surface became weakly hydrophobic with the second relatively stable wettable region of about $75^{\circ}$. When the temperature further increased to above $44^{\circ} \mathrm{C}$, the wettable region rise to about $85^{\circ}$, attributed to the competition between inter- and intra-molecular hydrogen bonds below and above the LCSTs of PNIPAM and PNIPMAM parts.

When the temperature is below $32^{\circ} \mathrm{C}$, the intermolecular hydrogen bonds between PNIPMAM- $b$-(PNI- 


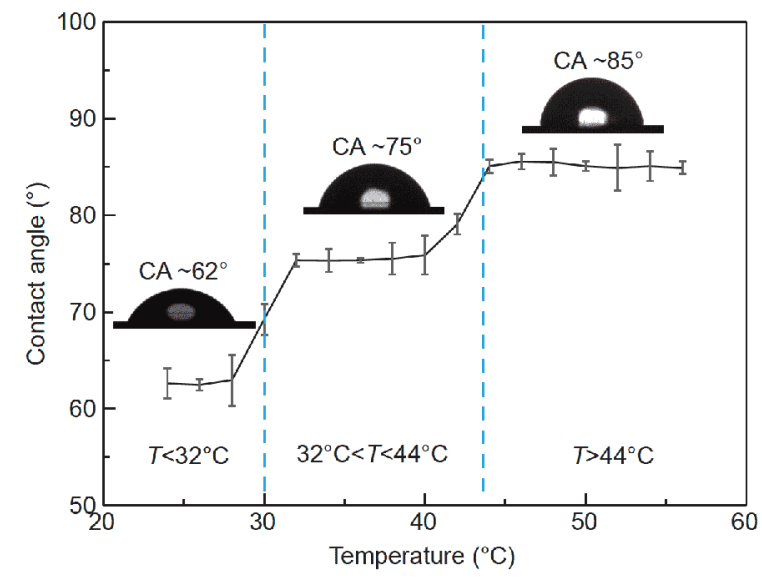

Figure 2 The wettability on PNIPMAM- $b$-(PNIPAM-co-PMAEP) brushes following temperature rising from 24 to $56^{\circ} \mathrm{C}$ at $\mathrm{pH} \sim 7.0$.

PAM-co-PMAEP) chains and water molecules contribute predominantly to the surface hydrophilicity. The polymer chains exhibit loose conformation (Fig. 3a). The corresponding adhesion force test was performed on ESweep Probe Station (Seiko instruments Inc, Japan) in AFM mode. The typical adhesion force at $24^{\circ} \mathrm{C}$ was around $114.2 \mathrm{pN}$ (Fig. $3 \mathrm{~d} 1$ ) and it was stable when the temperature was below $32^{\circ} \mathrm{C}$. When the temperature is higher than the LCST of PNIPAM $\sim 32^{\circ} \mathrm{C}$, but lower than that of PNIPMAM $\sim 44^{\circ} \mathrm{C}$, phase inversion of PNIPAM chains will occur at $32^{\circ} \mathrm{C}$, on which the inter-molecular hydrogen bonds change to intra-molecular hydrogen bonds. The hydrophilic amino and carbonyl groups are hard to interact with water molecules, which leads to a compact conformation (Fig. 3b). Meanwhile the lower PNIPMAM part in PNIPMAM- $b$-(PNIPAM-co-PMAEP) chains still exhibits loose conformation and no phase changes due to its LCST of about $44^{\circ} \mathrm{C}$. As reported $[39,43]$, the compact conformation of polymer brushes might induce relatively small adhesion force compared with the coiled polymer conformation. The adhesion force decreased sharply at $32^{\circ} \mathrm{C}$, and exhibited second stable stage at the temperature range between 32 and $44^{\circ} \mathrm{C}$ (Fig. 3d). Typical adhesion force at $38^{\circ} \mathrm{C}$ was about $78.8 \mathrm{pN}$ (Fig. 3d2). Further increasing temperature (higher than $44^{\circ} \mathrm{C}$ ) initiated phase inversion of the lower PNIPMAM (Fig. 3c), which resulted in further shrinkage of polymer chains. Consequently the whole PNIPMAM$b$-(PNIPAM-co-PMAEP) brushes transferred to more compact conformation. Because the close-packed PNIPMAM chains were located at the lower layer of PNIPMAM- $b$-(PNIPAM-co-PMAEP) brushes, the phase inversion confined in narrow space limited the further shrinkage relative to the whole polymer chains. The adhesion forces decreased sharply at $44^{\circ} \mathrm{C}$, and then presented the third stable stage. A typical adhesion force was $44.8 \mathrm{pN}$ at $50^{\circ} \mathrm{C}$ (Fig. $3 \mathrm{~d} 3$ ). Therefore it can be seen that the adhesion force was also presenting a three-stage change following temperature rising from 24 to $56^{\circ} \mathrm{C}$ (Fig. 3d). Moreover, the surface morphology of PNIPMAM- $b$-(PNIPAM-co-PMAEP) brushes at 24,38 and $50^{\circ} \mathrm{C}$ was homogeneous, but the surface roughness decreased slightly with the increase of temperature, which
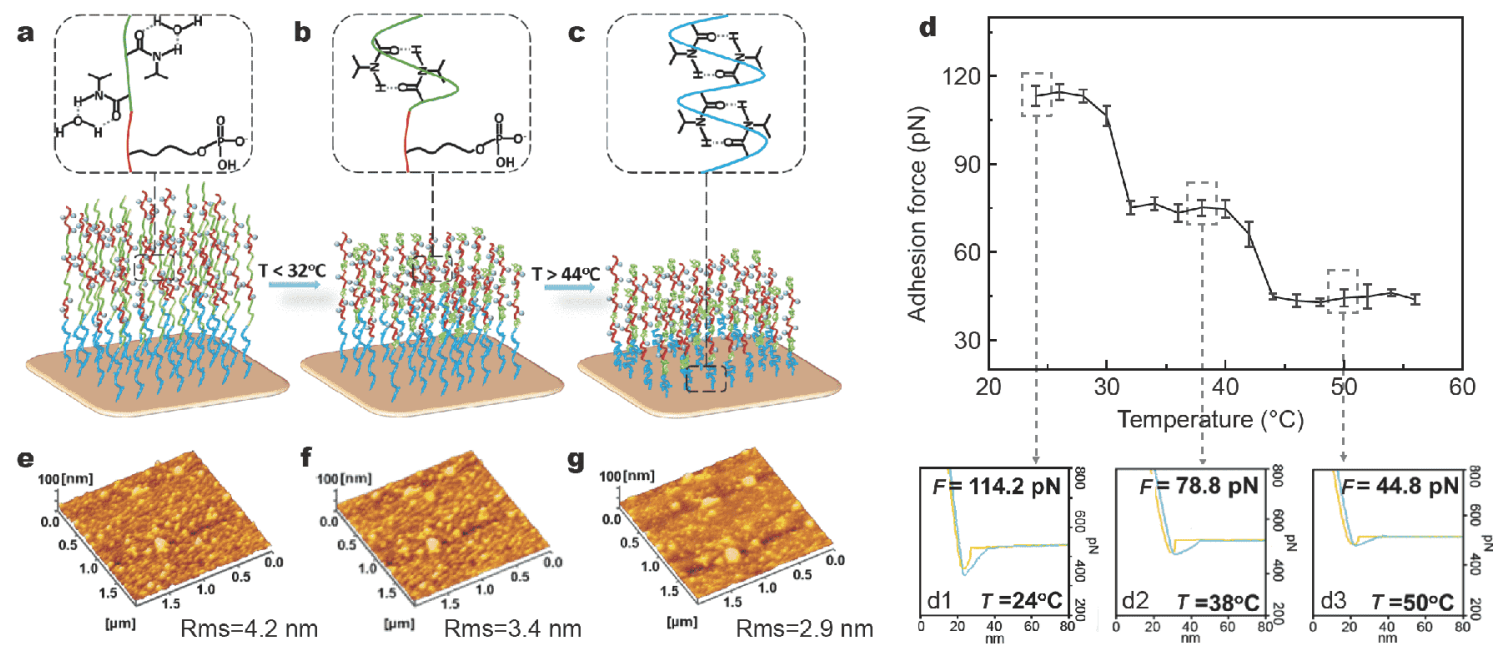

Figure 3 The possible conformation change corresponding to each temperature range (a): $T<32^{\circ} \mathrm{C},(\mathrm{b}): 32^{\circ} \mathrm{C}<T<44^{\circ} \mathrm{C},(\mathrm{c}): T>44^{\circ} \mathrm{C}$. (d) The adhesion force of PNIPMAM- $b$-(PNIPAM-co-PMAEP) brushes following temperature rising from 24 to $56^{\circ} \mathrm{C}$. (d1-d3) Typical adhesion force curve at three temperature set-points of 24,38 and $50^{\circ} \mathrm{C}$, respectively. (e-g) The typical AFM images of PNIPMAM- $b$-(PNIPAM-co-PMAEP) at 24,38 and $50^{\circ} \mathrm{C}$, respectively. 


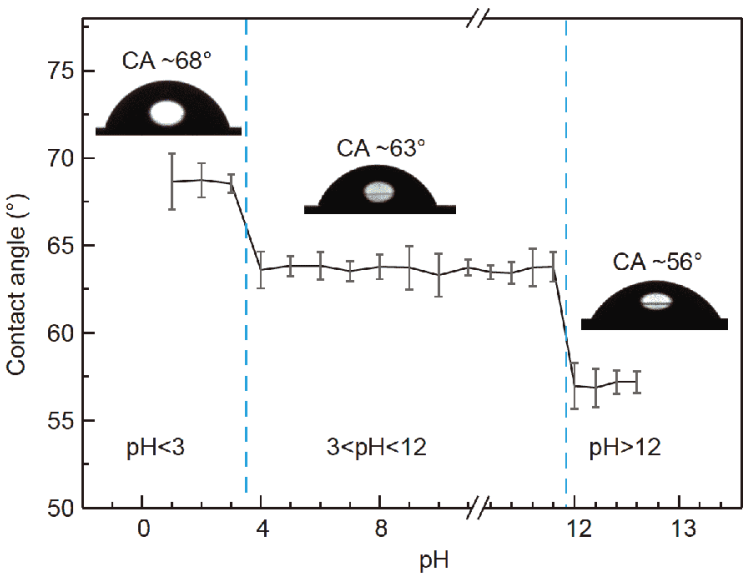

Figure 4 The wettability on PNIPMAM- $b$-(PNIPAM-co-PMAEP) brushes following $\mathrm{pH}$ change from 1.0 to 12.6 .

was $4.2,3.4$ and $2.9 \mathrm{~nm}$, respectively (Fig. $3 \mathrm{e}-\mathrm{g}$ ). It might be attributed to the constriction of polymer brushes, well consistent with those results of the temperatureresponsive wettability and adhesion force.

In addition, the inverse-designed polymer brushes PNIPAM- $b$-(PNIPMAM-co-PMAEP) was also fabricated. It only presented two stable wettable regions (below $32^{\circ} \mathrm{C}$ and above $44^{\circ} \mathrm{C}$ ) (Fig. S2a). CAs increased slowly between 32 and $44^{\circ} \mathrm{C}$; but no three-stage wettability could be found. The reason could be attributed to the limitation on conformation transition of the lower layer of PNIPAM chains in the dense package that could not bring the change in surface wettability.

The $\mathrm{pH}$-responsive wettable behavior of PNIPMAM- $b$ -
(PNIPAM-co-PMAEP) brushes is shown in Fig. 4. The surface CAs decreased with the increasing of $\mathrm{pH}$; and two wettable inflexions appeared at $\mathrm{pH}$ of around 3.0 and 12.0 , which were corresponding to the two $\mathrm{p} K_{\mathrm{a}}$ (4.5 and 7.7) of phosphate groups on PNIPMAM- $b$-(PNIPAM-coPMAEP) chains, respectively. In theory, $\mathrm{p} K_{\mathrm{a} 1} \sim 4.5$ of phosphate group is corresponding to the $\mathrm{pH}$ of 2.0. It shifts to 3.0 in this case, because the protonated freeenergy consumption of phosphate group is larger in confined space between close-packaged polyelectrolyte brushes than that in the bulk due to the electrostatic repulsions between the negative charges [38]. Three relatively stable wettable regions (about $68^{\circ}, 63^{\circ}$ and $56^{\circ}$ ) were shown corresponding to three $\mathrm{pH}$ ranges $(\mathrm{pH}<3.0$, $3.0<\mathrm{pH}<12.0, \mathrm{pH}>12.0$ ) (Fig. 4). Here the $\mathrm{pH}$ set-points used for CA investigation were chosen from 1 to 12.6, but not extended to 14 , because silicon substrate would be corroded in strong alkaline condition. The CAs would decrease sharply when $\mathrm{pH}$ was higher than 13.0 (Fig. S3a). The prepared polymer surface at $\mathrm{pH}$ of 14.0 (Fig. S3c) was much rougher than that of $\mathrm{pH}<13.0$ (Fig. S3b).

This $\mathrm{pH}$-responsive three-stage wettability change might be induced by the dissociation of phosphate group with the dependence of $\mathrm{pH}$. The dissociation process is exhibited in Fig. 5. When $\mathrm{pH}$ was below 3.0, the phosphate groups were completely protonated and presented as diacid $\left(\mathrm{R}-\mathrm{PO}_{4} \mathrm{H}_{2}\right)$ (Fig. 5a). The adhesion force at $\mathrm{pH} \sim 1.0$ was around $81.5 \mathrm{pN}$ (Fig. $5 \mathrm{~d} 1$ ). When $\mathrm{pH}$ was higher than 3.0, but lower than 12.0, first chemical equilibrium was broken, and the uncharged
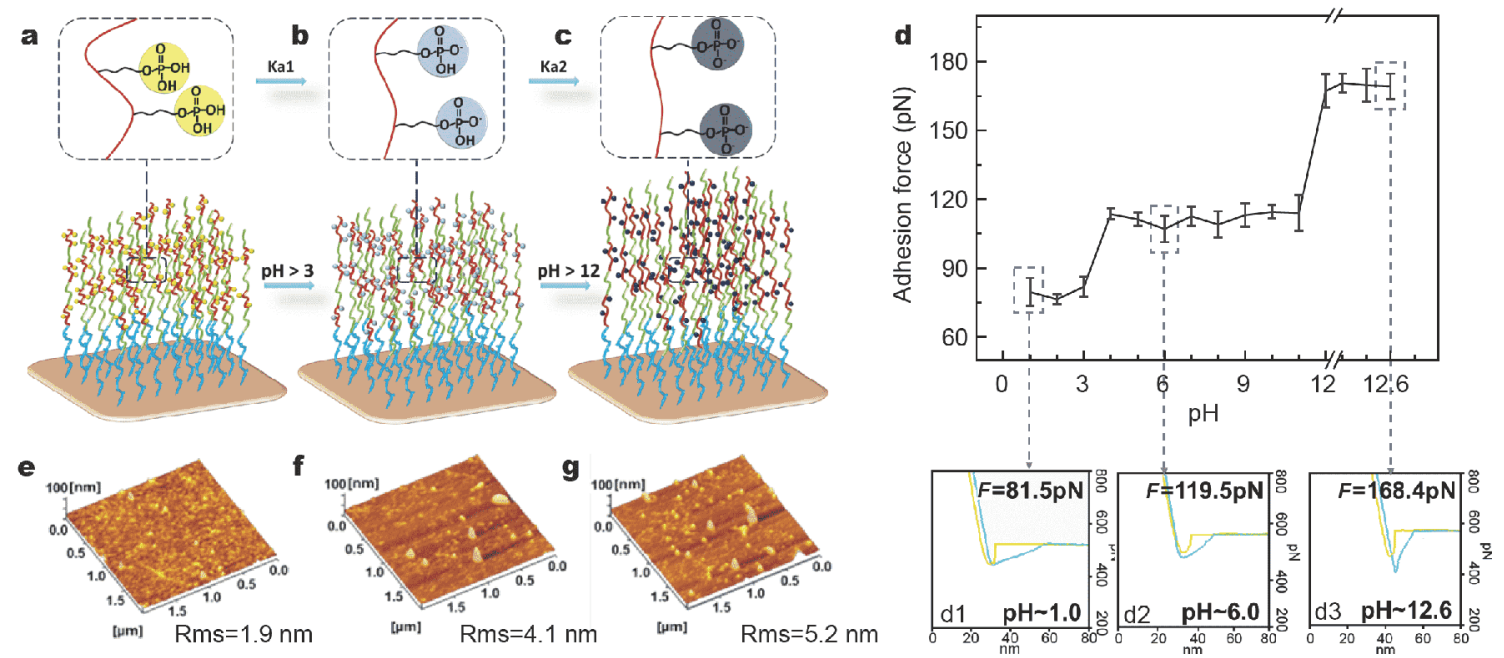

Figure 5 The dissociation of phosphate groups on PNIPMAM- $b$-(PNIPAM-co-PMAEP) chains following different $\mathrm{pH}$ : (a) $\mathrm{pH}<3.0$; (b) $3.0<\mathrm{pH}<12.0$; (c) $\mathrm{pH}>12.0$. (d) The relation between adhesion force and $\mathrm{pH}$ on PNIPMAM- $b$-(PNIPAM-co-PMAEP) brushes. (d1-d3) Typical adhesion force curve at three $\mathrm{pH}$ setpoints of 1.0, 6.0 and 12.6, respectively. (e-g) Typical AFM images of PNIPMAM- $b$-(PNIPAM-co-PMAEP) at pH of 1.0, 6.0 and 12.6, respectively. 


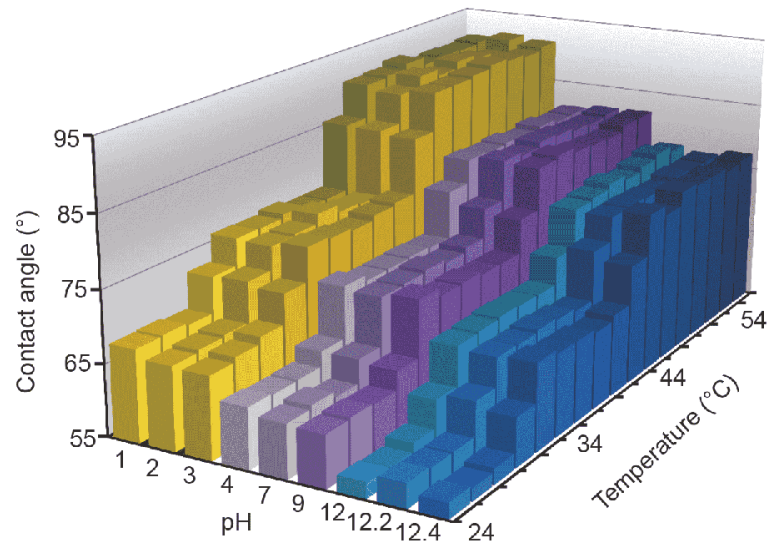

Figure 6 The multi-stage wettability of PNIPMAM- $b$-(PNIPAM-coPMAEP) film following temperature (from 24 to $56^{\circ} \mathrm{C}$ ) and $\mathrm{pH}$ (from 1.0 to 12.4 ). Three-stage wettability change could be observed following both temperature and $\mathrm{pH}$.

state changed to monovalent charged state $\left(\mathrm{R}-\mathrm{PO}_{4} \mathrm{H}^{-}\right)$ (Fig. 5b). The conformation of polymer chains spread due to the electrostatic repulsion. The adhesion force of polymer brushes at $\mathrm{pH} \sim 6.0$ increased to $119.5 \mathrm{pN}$ (Fig. $5 \mathrm{~d} 2$ ). The surface became hydrophilic simulaneously due to the increased hydrophilic groups of monovalent charged $\left(\mathrm{R}-\mathrm{PO}_{4} \mathrm{H}^{-}\right)$. When $\mathrm{pH}$ was higher than 12.0 , the monovalent charged state of phosphate groups would change to divalent charged state $\left(\mathrm{R}-\mathrm{PO}_{4}{ }^{2-}\right)$ ( Fig. $5 \mathrm{c}$ ). The electrostatic repulsion between polymer chains became much stronger compared to the diacidic and monovalent charged state, which resulted in more spread and loose conformation. The water molecules could contact with polymer brushes more easily. Consequently the adhesion force further increased to $168.4 \mathrm{pN}$ at $\mathrm{pH} \sim 12.6$ (Fig. 5d3). Three-stage in the adhesion force-pH curve (Fig. 5d) was well consistent with $\mathrm{pH}$-responsive threestage wettability on PNIPMAM- $b$-(PNIPAM-co-PMAEP) film. The AFM images in Fig. 5e-g exhibited the topography of the polymer film at $\mathrm{pH} \sim 1.0,6.0$ and 12.6, respectively. The roughness increased slightly from 1.9 to $5.2 \mathrm{~nm}$ that corresponded to the spreading conformation change of polymer chains at these three $\mathrm{pH}$ range. In addition, the inverse-designed PNIPAM- $b$ (PNIPMAM-co-PMAEP) brushes showed similar threestage wettability change with those on PNIPMAM- $b$ (PNIPAM-co-PMAEP) brushes, which could be attributed to that $\mathrm{pH}$-responsive PMAEP was on the upper layer of the whole brushes (Fig. S2b).

Detailed wettability change on PNIPMAM- $b$-(PNIPAM-co-PMAEP) film was investigated under different temperature and $\mathrm{pH}$ (Fig. 6). The prepared brushes was treated by aqueous solution with a certain $\mathrm{pH}$ value (1.0, $2.0,3.0,4.0,7.0,9.0,12.0,12.2$ and 12.4), and the CA was measured with temperature increased from 24 to $56^{\circ} \mathrm{C}$. It can be seen that, at each $\mathrm{pH}$, three-stage wettability appeared following temperature increase. Meanwhile, when temperature was fixed, three-stage wettability was also presented following $\mathrm{pH}$ change. It means that stable wettable regions can be regulated elaborately on the prepared PNIPMAM- $b$-(PNIPAM-co-PMAEP) film following temperature and $\mathrm{pH}$ change.

In conclusion, PNIPMAM- $b$-(PNIPAM-co-PMAEP) brushes were fabricated by ATRP. PNIPAM and PNIPMAM in the polymer chains endow the surface three-stage wettability following temperature; PMAEP in the polymer chains contributes to the $\mathrm{pH}$-responsive three-stage wettability. The adhesion force on the polymer film exhibits three-stage change. This work offers a possible way to construct multi-functional microfluidic devices under multi-triggers. Futher research may focus on integrating diversified stimulators for achieving multi-stage responsive surface.

Received 15 July 2018; accepted 19 September 2018;

published online 6 November 2018

1 Stuart MAC, Huck WTS, Genzer J, et al. Emerging applications of stimuli-responsive polymer materials. Nat Mater, 2010, 9: 101-113

2 Wang S, Liu K, Yao X, et al. Bioinspired surfaces with superwettability: new insight on theory, design, and applications. Chem Rev, 2015, 115: 8230-8293

3 Zhang D, Cheng Z, Kang H, et al. A smart superwetting surface with responsivity in both surface chemistry and microstructure. Angew Chem Int Ed, 2018, 57: 3701-3705

4 Liu M, Wang S, Jiang L. Nature-inspired superwettability systems. Nat Rev Mater, 2017, 2: 17036

5 Lei S, Wang F, Li W, et al. Reversible wettability between superhydrophobicity and superhydrophilicity of $\mathrm{Ag}$ surface. Sci China Mater, 2016, 59: 348-354

6 Cui Y, Li D, Bai H. Bioinspired smart materials for directional liquid transport. Ind Eng Chem Res, 2017, 56: 4887-4897

7 Han H, Lee JS, Kim H, et al. Single-droplet multiplex bioassay on a robust and stretchable extreme wetting substrate through vacuumbased droplet manipulation. ACS Nano, 2018, 12: 932-941

8 Ju J, Zheng Y, Jiang L. Bioinspired one-dimensional materials for directional liquid transport. Acc Chem Res, 2014, 47: 2342-2352

9 Liu HL, Wang ST. Poly( $N$-isopropylacrylamide)-based thermoresponsive surfaces with controllable cell adhesion. Sci China Chem, 2014, 57: 552-557

10 Banuprasad TN, Vinay TV, Subash CK, et al. Fast transport of water droplets over a thermo-switchable surface using rewritable wettability gradient. ACS Appl Mater Interfaces, 2017, 9: 2804628054

11 Sun T, Wang G, Feng L, et al. Reversible switching between superhydrophilicity and superhydrophobicity. Angew Chem, 2004, 116: $361-364$

$12 \mathrm{Xu}$ C, Wayland $\mathrm{BB}$, Fryd $\mathrm{M}$, et al. $\mathrm{pH}$-responsive nanostructures 
assembled from amphiphilic block copolymers. Macromolecules, 2006, 39: 6063-6070

13 Fu Y, Jin B, Zhang Q, et al. pH-induced switchable superwettability of efficient antibacterial fabrics for durable selective oil/water separation. ACS Appl Mater Interfaces, 2017, 9: 30161-30170

14 Wang B, Guo Z, Liu W. pH-responsive smart fabrics with controllable wettability in different surroundings. RSC Adv, 2014, 4: 14684-14690

15 Singh S, Friedel K, Himmerlich $\mathrm{M}$, et al. Spatiotemporal photopatterning on polycarbonate surface through visible light responsive polymer bound DASA compounds. ACS Macro Lett, 2015, 4: 1273-1277

16 Lim HS, Han JT, Kwak D, et al. Photoreversibly switchable superhydrophobic surface with erasable and rewritable pattern. J Am Chem Soc, 2006, 128: 14458-14459

17 Xie G, Li P, Zhao Z, et al. Light- and electric-field-controlled wetting behavior in nanochannels for regulating nanoconfined mass transport. J Am Chem Soc, 2018, 140: 4552-4559

18 Lahann J, Mitragotri S, Tran TN, et al. A reversibly switching surface. Science, 2003, 299: 371-374

19 Cantini E, Wang X, Koelsch P, et al. Electrically responsive surfaces: experimental and theoretical investigations. Acc Chem Res, 2016, 49: 1223-1231

20 Zheng X, Guo Z, Tian D, et al. Electric field induced switchable wettability to water on the polyaniline membrane and oil/water separation. Adv Mater Interfaces, 2016, 3: 1600461

21 Yang C, Wu L, Li G. Magnetically responsive superhydrophobic surface: in situ reversible switching of water droplet wettability and adhesion for droplet manipulation. ACS Appl Mater Interfaces, 2018, 10: 20150-20158

22 Lee S, Yim C, Kim W, et al. Magnetorheological elastomer films with tunable wetting and adhesion properties. ACS Appl Mater Interfaces, 2015, 7: 19853-19856

23 Drotlef DM, Blümler P, del Campo A. Magnetically actuated patterns for bioinspired reversible adhesion (dry and wet). Adv Mater, 2014, 26: 775-779

24 Song W, Xia F, Bai Y, et al. Controllable water permeation on a poly $(N$-isopropylacrylamide)-modified nanostructured copper mesh film. Langmuir, 2007, 23: 327-331

25 Zhang X, Shi F, Yu X, et al. Polyelectrolyte multilayer as matrix for electrochemical deposition of gold clusters: toward superhydrophobic surface. J Am Chem Soc, 2004, 126: 3064-3065

26 Li S, Li H, Wang X, et al. Super-hydrophobicity of large-area honeycomb-like aligned carbon nanotubes. J Phys Chem B, 2002, 106: 9274-9276

27 Miller JD, Veeramasuneni S, Drelich J, et al. Effect of roughness as determined by atomic force microscopy on the wetting properties of PTFE thin films. Polym Eng Sci, 1996, 36: 1849-1855

28 Genzer J, Efimenko K. Creating long-lived superhydrophobic polymer surfaces through mechanically assembled monolayers. Science, 2000, 290: 2130-2133

29 Feng L, Song Y, Zhai J, et al. Creation of a superhydrophobic surface from an amphiphilic polymer. Angew Chem Int Ed, 2003, 42: $800-802$

30 Xia F, Ge H, Hou Y, et al. Multiresponsive surfaces change between superhydrophilicity and superhydrophobicity. Adv Mater, 2007, 19: 2520-2524

31 Wang G, Han G, Wen Y, et al. Photo- and pH-responsive electrospun polymer films: wettability and protein adsorption characteristics. Chem Lett, 2015, 44: 1368-1370

32 Wang B, Liu HJ, Jiang TT, et al. Thermo-, and $\mathrm{pH}$ dual-responsive poly( $N$-vinylimidazole): Preparation, characterization and its switchable catalytic activity. Polymer, 2014, 55: 6036-6043

33 Xia F, Feng L, Wang S, et al. Dual-responsive surfaces that switch between superhydrophilicity and superhydrophobicity. Adv Mater, 2006, 18: 432-436

34 Hou X. Smart gating multi-scale pore/channel-based membranes. Adv Mater, 2016, 28: 7049-7064

35 Yuan W, Jiang G, Wang J, et al. Temperature/light dual-responsive surface with tunable wettability created by modification with an azobenzene-containing copolymer. Macromolecules, 2006, 39: $1300-1303$

36 Darmanin T, Guittard F. pH- and voltage-switchable superhydrophobic surfaces by electro-copolymerization of EDOT derivatives containing carboxylic acids and long alkyl chains. ChemPhysChem, 2013, 14: 2529-2533

37 Zhou F, Huck WTS. Three-stage switching of surface wetting using phosphate-bearing polymer brushes. Chem Commun, 2005, 165: 5999

38 Gilles FM, Tagliazucchi M, Azzaroni O, et al. Ionic conductance of polyelectrolyte-modified nanochannels: nanoconfinement effects on the coupled protonation equilibria of polyprotic brushes. J Phys Chem C, 2016, 120: 4789-4798

39 Song W, Li H, Wang C, et al. Design of multi-stage thermal responsive wettable surface. Adv Mater Interfaces, 2014, 1: 1400009

40 Liu H, Li Y, Sun K, et al. Dual-responsive surfaces modified with phenylboronic acid-containing polymer brush to reversibly capture and release cancer cells. J Am Chem Soc, 2013, 135: 7603-7609

41 Jalili K, Abbasi F, Milchev A. Surface microdynamics phase transition and internal structure of high-density, ultrathin PHEMA- $b$-PNIPAM diblock copolymer brushes on silicone rubber. Macromolecules, 2013, 46: 5260-5278

42 Matyjaszewski K, Xia J. Atom transfer radical polymerization. Chem Rev, 2001, 101: 2921-2990

43 Song W, Sun T, Song Y, et al. An atomic force microscopic investigation of electro-sensitive polymer surface. Talanta, 2005, 67: $543-547$

Acknowledgements This work was financially supported by the National Natural Science Foundation of China (21774044, 21425314, 21434009 and 21421061), Ministry of Science and Technology (2013YQ190467), and the Top-Notch Young Talents Program of China.

Author contributions Zhang S performed the experiments and tested the samples; Wang J did the preliminary ATRP experiments and performed the AFM measurement; Zhang X performed the AFM test with temperature control; Song W conceived the work and wrote the paper. Wang $S$ supervised the work. Zhang $S$ and Wang $J$ gave the equal contribution to the work.

Conflict of interest The authors declare no conflict of interest

Supplementary information Experiment section: FTIR of of monomer NIPAM, NIPMAM, MAEP; the wettability of inverse-designed PNIPAM- $b$-(PNIPMAM-co-PMAEP) brushes following temperature and $\mathrm{pH}$ and SEM images of the substrates at $\mathrm{pH} 12$ and 14 are available in the online version of the paper. 


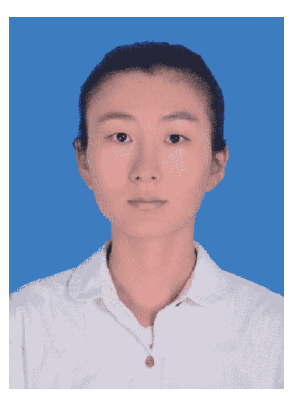

Shuang zhang received her BSc degree in polymer material and engineering from Changchun University of Technology 2017. Her research interest is the interaction between bio-inspired surface/interface.

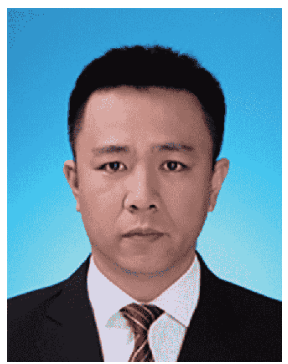

Wenlong Song received his BSc degree in applied chemistry in 2002 from Jilin University, China, and awarded his PhD degree in 2007 with Prof. Fengqi Liu and Prof. Lei Jiang under a joint course of the College of Chemistry, Jilin University and the Institute of Chemistry, Chinese Academy of Sciences (ICCAS). Then he worked as a postdoctoral fellow in 3B's group-Biomaterials, Biodegradables and Biomimetics in Minho University of Portugal. In 2011, he joined the State Key Laboratory of Supramolecular Structure and Materials, Jilin University. His research interest is focused on: (i) investigating the interaction between bioinspired surface/interface and cells; (ii) constructing biomimetic hydrogels for artificial cartilage.

\section{温度和pH触发的可调多级浸润和粘附力聚合物刷}

张爽 ${ }^{1 \dagger}$, 王健 ${ }^{1 \dagger}$, 张雪巍 ${ }^{1}$, 宋文龙 ${ }^{{ }^{*}}$, 王树涛 ${ }^{2,3}$

摘要 智能响应性可以将丰富的功能集成到微流体器件中; 同时在刺激前后稳定的润湿区域赋予微流体器件稳定的功能表达. 因此在微 流体器件领域，如何构建具有多重响应的多梯度润湿表面仍然是目前面临的一个巨大挑战. 本文应用原子转移自由基聚合方法在硅基底 上制备聚 $(N$-异丙基甲基丙烯酰胺)- $b$-( $N$-异丙基丙烯酰胺)-co-2-(甲基丙烯酰氧基)乙基磷酸)聚合物刷. 通过对温度和 $\mathrm{pH}$ 值的控制, 在聚 合物表面实现了浸润性的多级梯度变化. 同时, 伴随着温度和 $\mathrm{pH}$ 值的变化, 聚合物刷表面的粘附力也表现为多级梯度变化. 这种多重响应 的多级梯度变化的聚合物刷将为多功能微流体和生物分析器件的构建提供一种新方法. 